\title{
Control of dissolved oxygen in northern temperate lakes over scales ranging from minutes to days
}

\author{
O. C. Langman ${ }^{1, *}$, P. C. Hanson ${ }^{1}$, S. R. Carpenter ${ }^{1}$, Y. H. Hu ${ }^{2}$ \\ ${ }^{1}$ Center for Limnology, University of Wisconsin, Madison, 680 North Park Street, Madison, Wisconsin 53706, USA \\ ${ }^{2}$ Department of Electrical and Computer Engineering, University of Wisconsin, Madison, 1415 Engineering Drive, Madison, \\ Wisconsin 53706, USA
}

\begin{abstract}
Dissolved oxygen (DO) observations from in situ sensors show complex temporal patterns, suggesting that the balance of control by underlying processes changes across scales. At scales ranging from minutes to days, a number of physical and biological processes, such as internal waves, mixing, and ecosystem metabolism, may impart pattern on observed DO. In discriminating the control over DO variability by scale, this helps us to reduce uncertainty in estimates of important ecosystem rates, such as gross primary production and respiration. In this study, we examined DO variability over scales ranging from minutes to days and assessed the relative contributions from several physical and biotic drivers. High frequency measurements of DO, wind, temperature, and photosynthetically available radiation (PAR) were obtained over periods of approximately $4 \mathrm{~d}$ from 25 lakes in northern Wisconsin. Patterns in data were isolated by time scale through wavelet transforms. A suite of predictors were related to DO across time scales using artificial neural networks. At the diel scale, PAR explained most of the variability in DO signals. At sub-diel scales, temperature and wind largely explained variability in DO. However, the nature, strength, and time scale of the relationships between drivers and DO may be a function of lake size.
\end{abstract}

KEYWORDS: Dissolved oxygen $\cdot$ High frequency sensing $\cdot$ Continuous wavelet transform $\cdot$ Northern temperate lakes

\section{INTRODUCTION}

Dissolved oxygen (DO) in the surface waters of north temperate lakes is influenced by a suite of exogenous drivers derived from climatic, terrestrial, and anthropogenic sources, each affecting DO through processes that operate on unique time scales. Scale-dependent control has been identified in long-term DO time series, with annual and decadal variability relating to temperature variation, and seasonal variability relating to temperature and external loading (Hanson et al. 2006). Within-season, scale-dependent control of DO has been shown to relate to thermal structure, irradiance, and nutrient availability (Staehr \& Sand-Jensen 2007). At time scales of days, it has been assumed that photosynthesis, driven by irradiance, and respiration control DO variability. This assumption underlies ap- plications of Odum's (1956) model in estimating ecosystem metabolism in the surface waters of lakes (Cole et al. 2000, Hanson et al. 2003, Lauster et al. 2006, Coloso et al. 2008). However, high frequency DO measurements made over days show complex patterns, suggesting that DO may be controlled by multiple mechanisms that include a mix of biological and physical processes (Eckert et al. 2002, Hanson et al. 2008).

At the sub-diel scale, several non-biological processes may be important in controlling DO in the surface waters of lakes. Internal waves, which can displace substantial vertical physical and chemical gradients (Hodges et al. 2000, Boegman et al. 2003), may appear as time-varying DO patterns (Hanson et al. 2008). Localized wind (Podsetchine \& Schernewski 1999) and abrupt changes in weather (Saggio \& Imberger 1998) can cause mixing across large DO gradi- 
ents and at interfaces critical to nutrient fluxes (MacIntyre et al. 2009). Differential heating and cooling in lakes can initiate horizontal water flow (MacIntyre et al. 2002) and alter gas exchange coefficients that control air-water gas flux (Jonsson et al. 2008). Understanding how these complex interactions are manifested in high-frequency DO signals will help us interpret data from lake sensor networks (Kratz et al. 2006), leading to a better understanding of important short-term dynamics, such as quantification of metabolic rates related to the wax and wane of phytoplankton blooms.

The complexity of high-frequency signals challenges our ability to connect patterns from exogenous drivers to patterns in observed DO. Isolating pattern into time scales of variability may help reduce confounding effects of patterns at other scales. For example, Keitt \& Fischer (2006) used wavelet transforms to demonstrate scale-dependent synchrony and compensation in zooplankton. For DO, it is easy to imagine that internal waves may create a periodic pattern at the hourly scale, whereas advective mixing from heating and cooling may cause a pattern related to cloud cover or sunrise and sunset. These sub-daily patterns should be separable from commonly observed diel patterns that result from irradiance-driven metabolism. However, observed variability likely depends on lake characteristics. For example, lakes of differing size have differing internal wave periods (Thorpe \& Jiang 1998); lakes rich in organic carbon experience rapid heating and cooling (Houser 2006); and metabolic rates vary dramatically across nutrient gradients in lakes (Hanson et al. 2003). Relating patterns in exogenous drivers with lake DO will require a flexible analytical approach that accounts for scale-dependent control that may differ among lakes.

In the present study, we explored how control over DO variability in the surface waters of northern Wisconsin lakes changes across time scales from minutes to days. We isolated time scales of variability using wavelet transforms and use artificial neural networks to determine the relative importance of irradiance, wind, and temperature as correlates of DO. By analyzing high-frequency data from 25 lakes, we assessed how DO control changes across broad gradients in lake size. In most lakes, a scale-specific pattern in exogenous drivers appears in DO signals, but in ways mediated by lake size.

\section{METHODS}

We addressed control over time-dependent variability of surface-water DO in 3 steps. First, we isolated scales of variability from minutes to days in all variables, using wavelet transforms. This helps reduce the confounding influence of any one time scale, for example the diel scale, on our analyses of other scales. Secondly, we tested whether scale-specific pattern in DO relates to scale-specific pattern in a suite of driving variables. Testing these relationships is particularly challenging because the predominance of any one process in controlling DO could change by scale, and for any one scale could differ among lakes. Thus we did not assume relationships between drivers and DO a priori. Instead, empirical linkages were allowed to develop within the model, which in this case is an artificial neural network (ANN). We used ANNs to map driver influence across temporal scale and, when multiple lakes were considered, also ranges of lake characteristics. Finally, we looked for broad patterns in driver-DO relationships across all 25 lakes.

Study site. The data were sampled in 2000 from 25 temperate lakes in northern Wisconsin (Table 1). The lakes were originally chosen to cover a wide range of dissolved organic carbon (DOC) and total phosphorus (TP) concentrations but also span wide ranges in total area. Sampling methods have been described in detail

Table 1. Characteristics of the 25 lakes included in the present study. TP: total phosphorus; DOC: dissolved organic carbon; abs: absorbance. Source: Hanson et al. 2003

\begin{tabular}{|lrrrrrr|}
\hline Lake & $\mathrm{pH}$ & $\begin{array}{c}\text { Area } \\
\text { (ha) })\end{array}$ & $\begin{array}{c}\mathrm{TP} \\
\left(\mathrm{mg} \mathrm{m}^{-3}\right)\end{array}$ & $\begin{array}{c}\mathrm{DOC} \\
\left(\mathrm{g} \mathrm{m}^{-3}\right)\end{array}$ & $\begin{array}{c}\text { Chlorophyll } \\
\left(\mathrm{mg} \mathrm{m}^{-3}\right)\end{array}$ & $\begin{array}{c}\text { Color } \\
(\mathrm{abs} 440 \mathrm{~nm})\end{array}$ \\
\hline Allequash & 168.4 & 39.8 & 3.7 & 9.6 & 1.2 & 7.2 \\
Big Muskellunge & 396.3 & 9.4 & 4.5 & 4.5 & 0.3 & 6.8 \\
Brown & 32.9 & 55.9 & 9.1 & 13.2 & 3.7 & 7.5 \\
Crampton & 25.8 & 13.2 & 4.0 & 4.1 & 0.6 & 5.9 \\
Cranberry Bog & 1.4 & 17.9 & 11.5 & 22.6 & 7.9 & 4.7 \\
Crystal & 36.7 & 4.4 & 1.6 & 2.7 & 0.1 & 5.8 \\
East Long & 2.3 & 23.2 & 12.4 & 14.7 & 9.3 & 5.5 \\
Helmet & 2.8 & 19.9 & 20.3 & 3.5 & 23.1 & 5.5 \\
Hiawatha & 14.6 & 20.2 & 17.5 & 13.6 & 14.5 & 6.9 \\
Hummingbird & 0.8 & 34.3 & 20.3 & 19.8 & 19.6 & 4.9 \\
Kickapoo & 7.9 & 34.9 & 14.2 & 14.3 & 9.6 & 6.6 \\
Little Arbor Vitae & 216.1 & 105.3 & 3.2 & 56.9 & 0.7 & 8.5 \\
Mary & 1.2 & 18.6 & 21.7 & 25.1 & 13.8 & 5.9 \\
Muskellunge & 110.0 & 78.3 & 5.0 & 18.4 & 1.8 & 7.2 \\
Northgate Bog & 0.3 & 15.3 & 24.6 & 2.7 & 20.4 & 4.2 \\
Paul & 1.7 & 11.0 & 6.5 & 4.2 & 1.6 & 6.3 \\
Peter & 2.7 & 21.3 & 6.4 & 30.2 & 1.8 & 9.0 \\
Plum & 91.0 & 28.0 & 4.7 & 10.3 & 0.9 & 7.7 \\
Reddington Bog & 1.2 & 34.0 & 23.1 & 17.6 & 22.8 & 5.9 \\
Sparkling & 64.0 & 16.8 & 3.1 & 2.4 & 0.3 & 6.8 \\
Tenderfoot & 165.2 & 42.5 & 7.8 & 17.3 & 2.8 & 7.7 \\
Trout Bog & 1.1 & 29.3 & 17.0 & 38.8 & 13.4 & 4.6 \\
Trout Lake & 1090.9 & 25.2 & 2.2 & 3.0 & 0.3 & 7.4 \\
Ward & 2.7 & 28.1 & 7.0 & 5.8 & 2.7 & 7.2 \\
West Long & 5.5 & 13.8 & 6.6 & 7.6 & 3.6 & 5.9 \\
\hline
\end{tabular}


in Hanson et al. (2003). A brief description follows. An automated sampling buoy was used to record DO, water temperature, photosynthetically available radiation (PAR), and wind speed at $15 \mathrm{~min}$ intervals for durations ranging from 2.5 to $4 \mathrm{~d}$ per lake. Sampling durations were not coincident between lakes. DO instantaneous measurements were made at $0.5 \mathrm{~m}$ depth using a YSI model 600-XLM sonde using a Rapid Pulse oxygen probe (model 6562) and temperature sensor. Wind speed was measured $1 \mathrm{~m}$ above the lake using a RM Young model 03001 anemometer, and PAR was measured $10 \mathrm{~cm}$ above the lake surface using a Li-Cor model 190SA quantum sensor. One min discrete samples were averaged over 15 min intervals for both PAR and wind speed. The DO probe was calibrated in air prior to deployment with a correction for barometric pressure, and again after retrieval. A linear drift model was used to correct the DO data for drift.

Continuous wavelet transform. Multiresolution analysis was accomplished by applying the continuous wavelet transform (CWT) to the source data (Fig. 1). The crucial component of CWT is that its basis functions are time variant, allowing for the decomposition of the original signal into multiple component signals, each of which represents a frequency with amplitude that varies through time. The complex Mexican hat basis function was chosen for its high temporal precision (Addison 2002). No further modifications to the wavelet were needed because data were sampled at regular intervals and had no sampling gaps. Edge effects were mitigated by the zero padding technique (Addison 2002). All variables were wavelet-transformed into 130 discrete scales, producing 130 sets of data for each lake, containing DO, wind, temperature, and PAR data that correspond to scales of $15 \mathrm{~min}$ through $30 \mathrm{~h}$. Subsequent analyses were performed at each scale independent of other scales.
Artificial neural network. Analysis of a single scale was accomplished by relating the transformed PAR, wind speed, and water temperature to DO via an ANN (Fig. 1). We chose an ANN because it allowed us to simultaneously search the model space and parameter space to obtain the best model, given the complexity of the data. Neural networks are known to be efficient at searching parameter space when trained with complex data, such as variables measured by a sensor network. Combined with model selection algorithms, the neural network can also examine model space (Haykin 1994). Each time scale of the transformed data was considered independently using a separate neural network. The neural network was a feed-forward network that used a back-propagation learning algorithm. The 6 inputs to the system consisted of the current time-scale levels of PAR, wind speed, and water temperature, as well as one lag for each of these potential drivers. The lags were based on the time scale of interest; they corresponded to a phase shift of one quarter of the wavelength for that time scale. The quarter wavelength phase was chosen because of known lags between drivers and response variables in lakes. For example, as PAR increases through the day, so does DO. However, PAR peaks near midday, but DO tends to peak near dusk, even though PAR is known to drive an increase in DO due to primary productivity (Hanson et al. 2003). This consideration of a single lag for each driver was done primarily to limit the complexity of the neural network. Data were normalized to a range of -1 to 1 prior to development of the neural network due to the limits of the activation function. The activation function chosen was the hyperbolic tangent function, due to its training advantages against non-sigmoid functions and because the better numerical conditioning offered by the -1 to 1 range allowed for faster training.

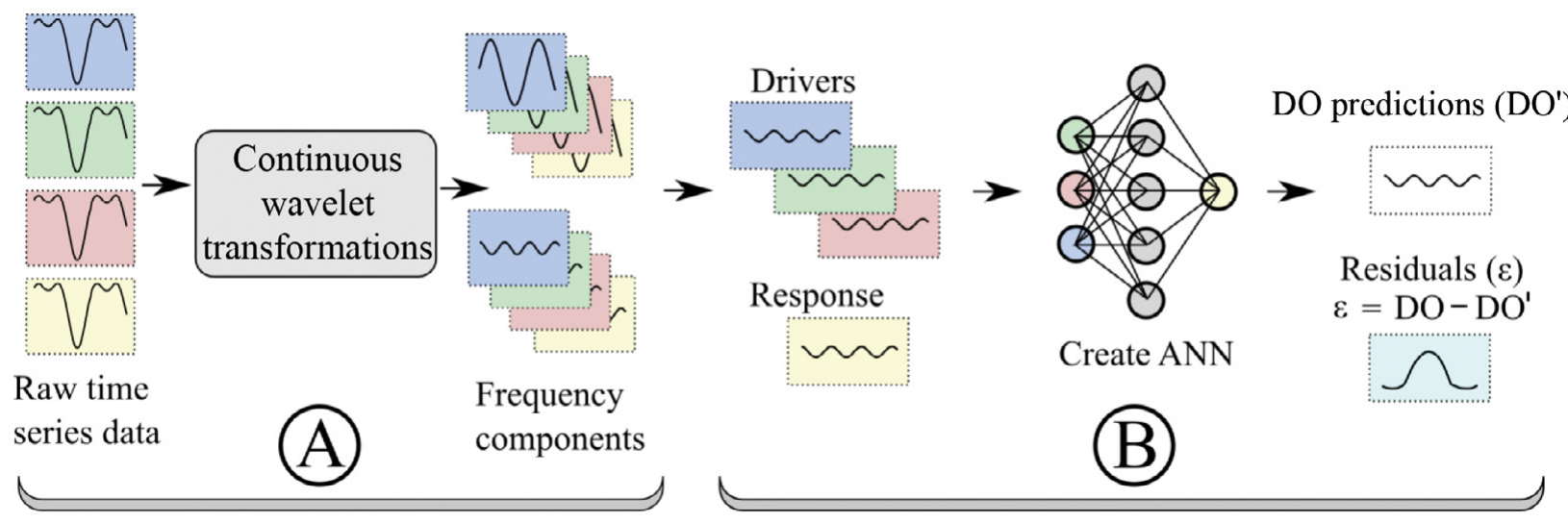

Fig. 1. Visual overview of the 2-step modeling process. (A) Time series data, both driver and response variables, are decomposed into frequency components of the original signal via a continuous wavelet transformation. (B) Each set of frequency components is then used to create an artificial neural network (ANN) model. Dissolved oxygen (DO) is defined as a function of the drivers and DO' the predictions of the ANN model. Residuals are calculated as the difference between predictions and observations 
Overfitting is a potential issue when using a neural network approach. The technique called Optimal Brain Damage (OBD; Le Cun et al. 1990) was used to remove unimportant weights from the network. This reduced the number of parameters in the network and resulted in better generalization. While a reduced network size does not always lead to better generalization (Barkai et al. 1993), OBD modified networks showed increased generalization performance and further reduced training time. Early stopping (Caruana et al. 2000) was also investigated and it produced results that were similar in their generalization capacity, but did not offer the advantages of a less complex network or reduced training time.

Bootstrapping and finishing. To test the importance of driver variables in controlling DO at each time scale, the fitted ANN at each time scale was used to model the DO response to perturbations in each of the driver variables. The significance of the DO response was determined through a bootstrapping procedure (Fig. 2). Neural networks were constructed as before, using the source data with residuals that were calculated from the output of the initial neural network. For each resulting network, a nominal set of input data was constructed by using the means of the respective source data which was then run through the current bootstrap iteration neural network to obtain a DO prediction. One component of the nominal data was then perturbed (PAR, wind speed, or water temperature) by $10 \%$ of its initial value and run through the neural network. The resulting values were compared against the unperturbed nominal DO prediction using a simple Z-statistic. The bootstrap process was repeated 1000 times to capture the range of potential models. The results created a distribution that described the magnitude and variation of the effects of each potential driver of DO at a specific time scale. This distribution was further compressed by reducing it to the $Z$-statistic of 0 for the distribution. When assembled for a single driver for a specific lake, the result is a 2-dimensional representation of the magnitude of importance for a single driver of DO over all of the examined time scales of a lake.

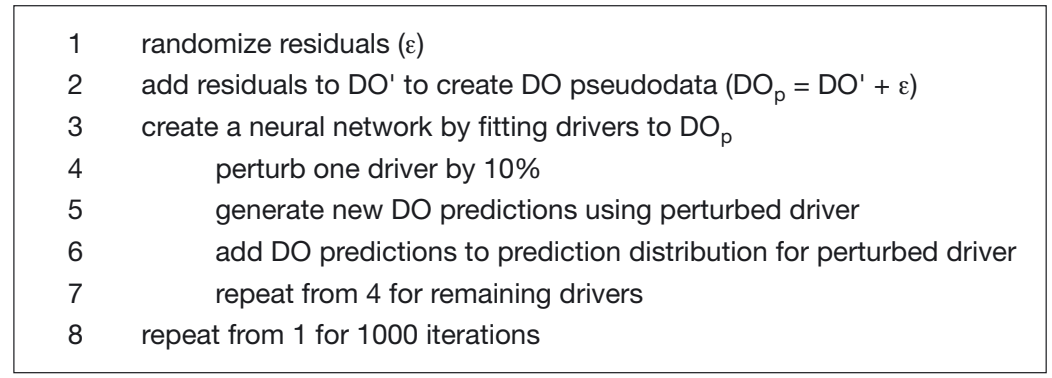

Fig. 2. Pseudocode representation of the bootstrap process. The inputs correspond to one scale of the wavelet decomposition for one lake. These inputs (DO', $\varepsilon$, and the decomposed drivers) are output from the process described in Fig. 1. The outputs of the bootstrapping process are one distribution per driver per level of decomposition that indicates both the direction and magnitude of effect of the driver on dissolved oxygen (DO) at a specific scale
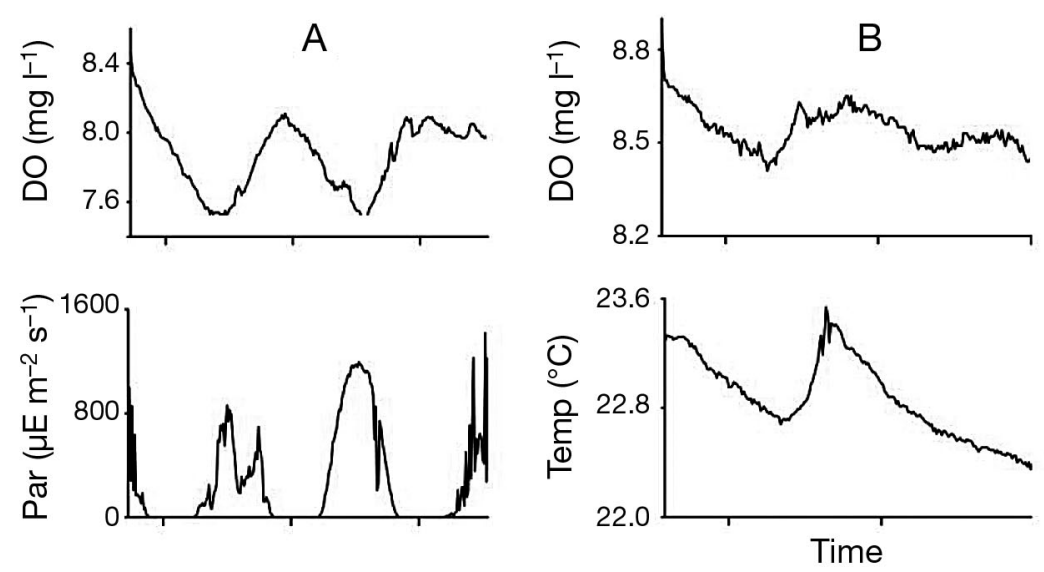

\section{RESULTS}

Examples from 3 lakes showed pattern at multiple time scales prior to wavelet transformation (Fig. 3). Allequash Lake demonstrated a DO signal dominated by a strong diel fluctuation related to the cycles in PAR that are somewhat out of phase. However, higher frequency variability in the DO signal appears to be unrelated to PAR. Trout Bog exhibited a similar but less pronounced diel signal, as well as a trend occurring over the length of the
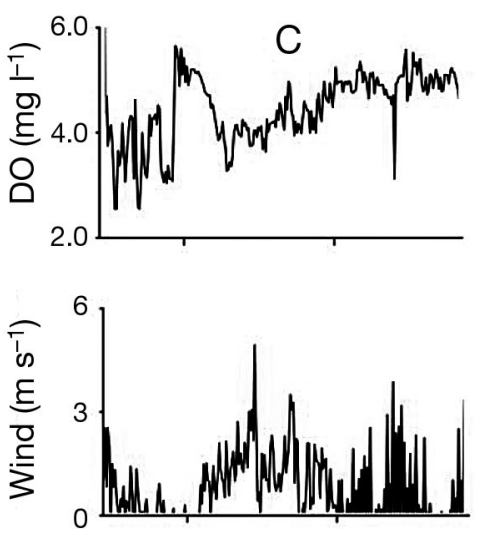

Fig. 3. Raw data for 3 lakes chosen as exemplar lakes: (A) Allequash Lake, (B) Trout Bog, and (C) Hummingbird Lake. The top plots show dissolved oxygen (DO), while the bottom plots show a driver that was particularly powerful in the explanation of variability in DO for the lake. Tick marks on the x-axis indicate midnight. PAR: photosynthetically available radiation 
sampling period that appears correlated with water temperature. Hummingbird Lake had highly variable DO, showing little diel pattern. These 3 lakes were chosen as exemplars and are used repeatedly to demonstrate different stages of the analyses.

\section{Wavelet transformations}

The global wavelet spectra for the 3 exemplar lakes (Fig. 4) highlight the DO scales apparent in the original time series (Fig. 3). The horizontal dashed line in Fig. 4 is the power threshold above which the variability of DO is significantly different from red noise, which takes into account the increasing power density of noise as the frequency increases. Allequash Lake has the most power at approximately the diel scale. Trout Bog shows significant power at short time scales (5 and $12 \mathrm{~h}$ ), as well as at the diel scale. Hummingbird Lake shows moderate power at the diel scale, pronounced power at the $12 \mathrm{~h}$ scale, and small but significant power at the $2 \mathrm{~h}$ scale. Due to the length of the sampling, effects at scales longer than $32 \mathrm{~h}$ are likely edgeeffect occurring during the wavelet transformation. The figure axes have been truncated accordingly. Because the global wavelet spectra collapse the time axis to calculate power, they were not used in the ANN analysis. However, the global wavelet spectra are useful for summarizing the scales at which a given variable has pattern in each lake. This information can also be inferred from the white space in the 2-dimensional influence charts (see Figs. 5-7). If a driver has no significant relationship with a response variable at a given scale, that scale appears white in the chart. Often this corresponds to scales in the global wavelet spectra in which power does not exceed the significance threshold line, as shown in Fig. 4.

After wavelet transformation, relationships between drivers and DO at specific frequencies appear. Allequash
Lake has a distinct positive relationship between PAR and light at the diel scale, and Trout Bog similarly has a strong relationship between water temperature and DO. Hummingbird Lake has DO pattern at the $2.5 \mathrm{~h}$ scale that appears to relate to wind at that scale. At various points within the decomposition the directionality of the relationship inverts and the magnitude of the wind pulses do not directly match with DO. Many lakes exhibit a significant diel spike at the $24 \mathrm{~h}$ scale, but the magnitude and resolution of this spike varies widely between lakes.

\section{Model results}

The results of the bootstrapping ANN analyses are plotted in Figs. 5-7. There is one plot for each of the 3 drivers. The abscissa in each plot are lakes ordered by lake area. The ordinates are the 130 time scales, ranging from 0.5 to $32 \mathrm{~h}$. The significance of the relationship between the driver and DO is represented by the color plotted: red indicates a strong positive relationship, blue indicates a strong negative relationship, and absence of color indicates no significant relationship.

Light exhibited a strong positive band around the diel time scale (Fig. 5). The strength of the signal varied across the selection of lakes, with some of the smaller lakes, including Hummingbird Lake (Fig. 5A), exhibiting little significant relationship between PAR and DO. The other lakes generally exhibited diel significance, but the magnitude of the interaction varied between lakes with no discernible pattern. Negative significance appears in several lakes both below the diel band for time scales between 10 and $22 \mathrm{~h}$, and above between $27.5 \mathrm{~h}$ and the maximum $32 \mathrm{~h}$ time scale.

Temperature significance (Fig. 6) appears most often for scales corresponding to $7.5 \mathrm{~h}$ and scales between $20 \mathrm{~h}$ and the maximum scale. Both of these divisions contain lakes that display either positively or nega-
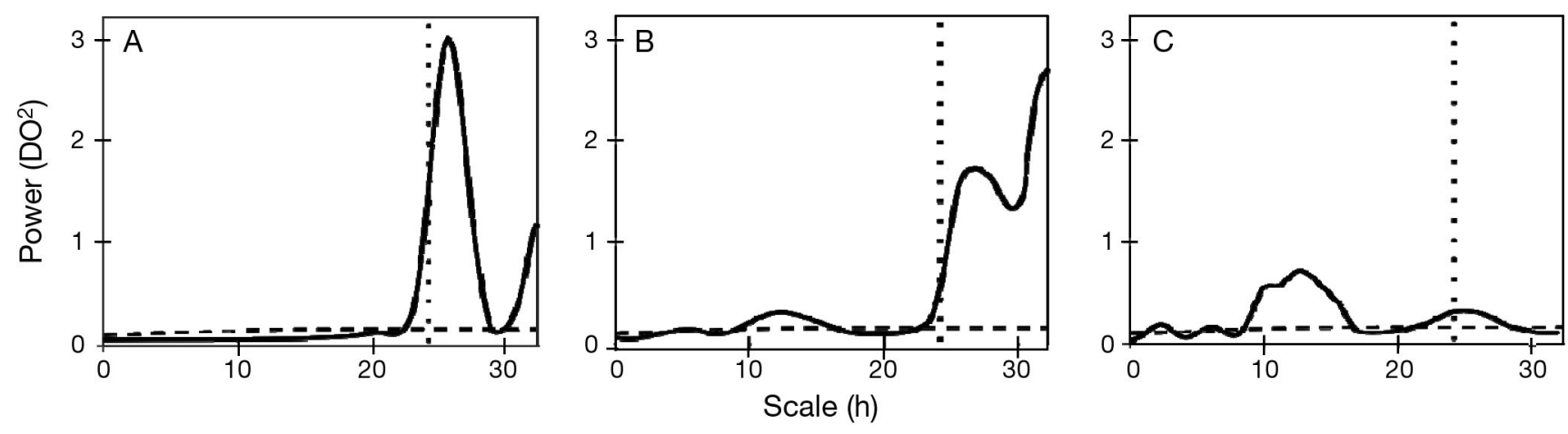

Fig. 4. Global wavelet spectra for 3 lakes chosen as exemplar lakes: (A) Allequash Lake, (B) Trout Bog, and (C) Hummingbird Lake. Similar to a Fourier power spectrum, the global wavelet spectrum is an indicator of the dominant components in a signal. The horizontal dashed line is the significance threshold. The vertical dotted line indicates the $24 \mathrm{~h}$ (diel) scale. DO: dissolved oxygen 


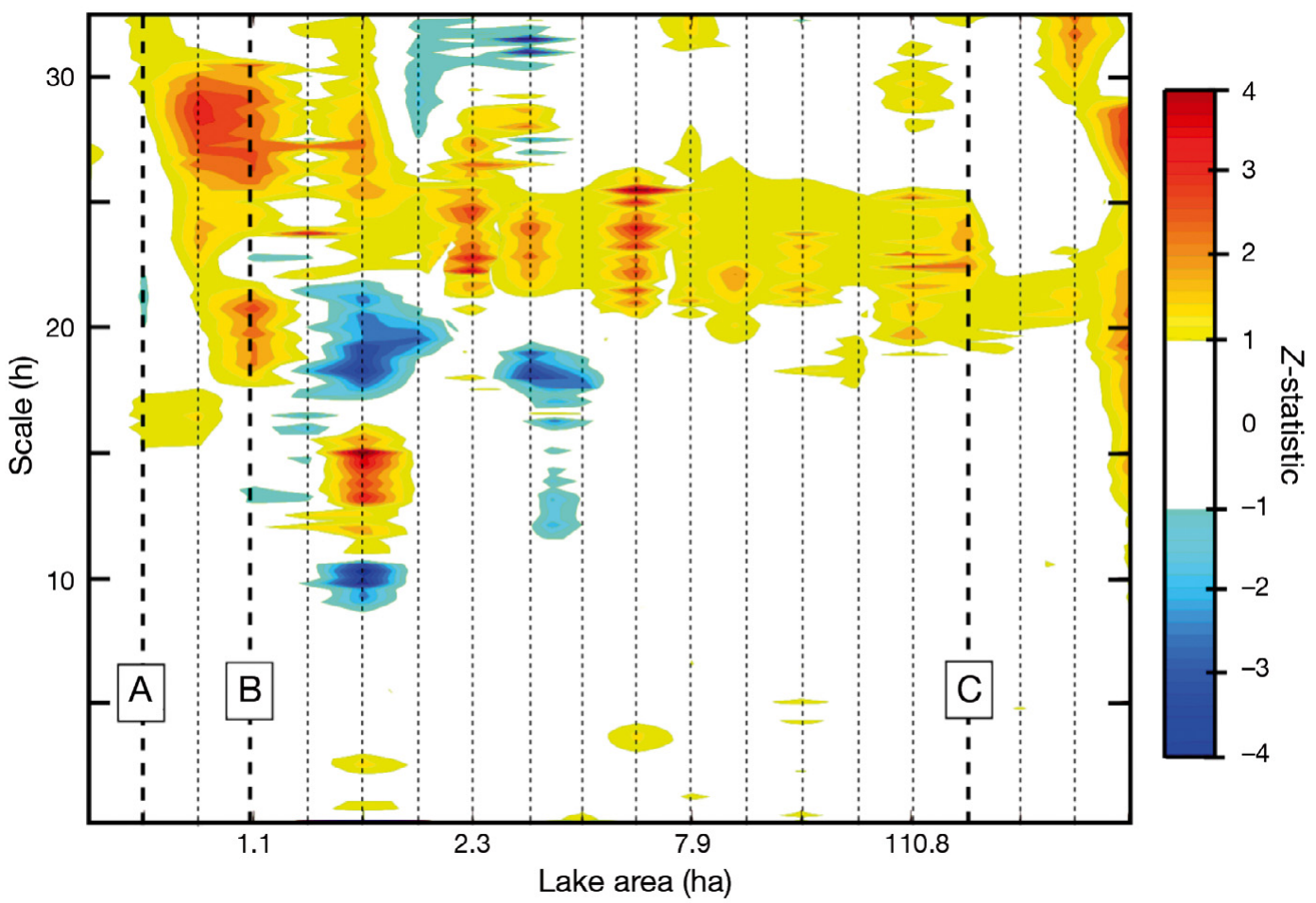

Fig. 5. Photosynthetically available radiation correlation with dissolved oxygen (DO) for scales from 0.25 to $32 \mathrm{~h}$. Each lake is represented by a vertical dashed line. Labeled lines indicate the lakes that are featured in the analysis; A: Hummingbird Lake, B: Trout Bog, and C: Allequash Lake. White space represents areas where the driver had no significant effect on DO. The x-axis is categorical

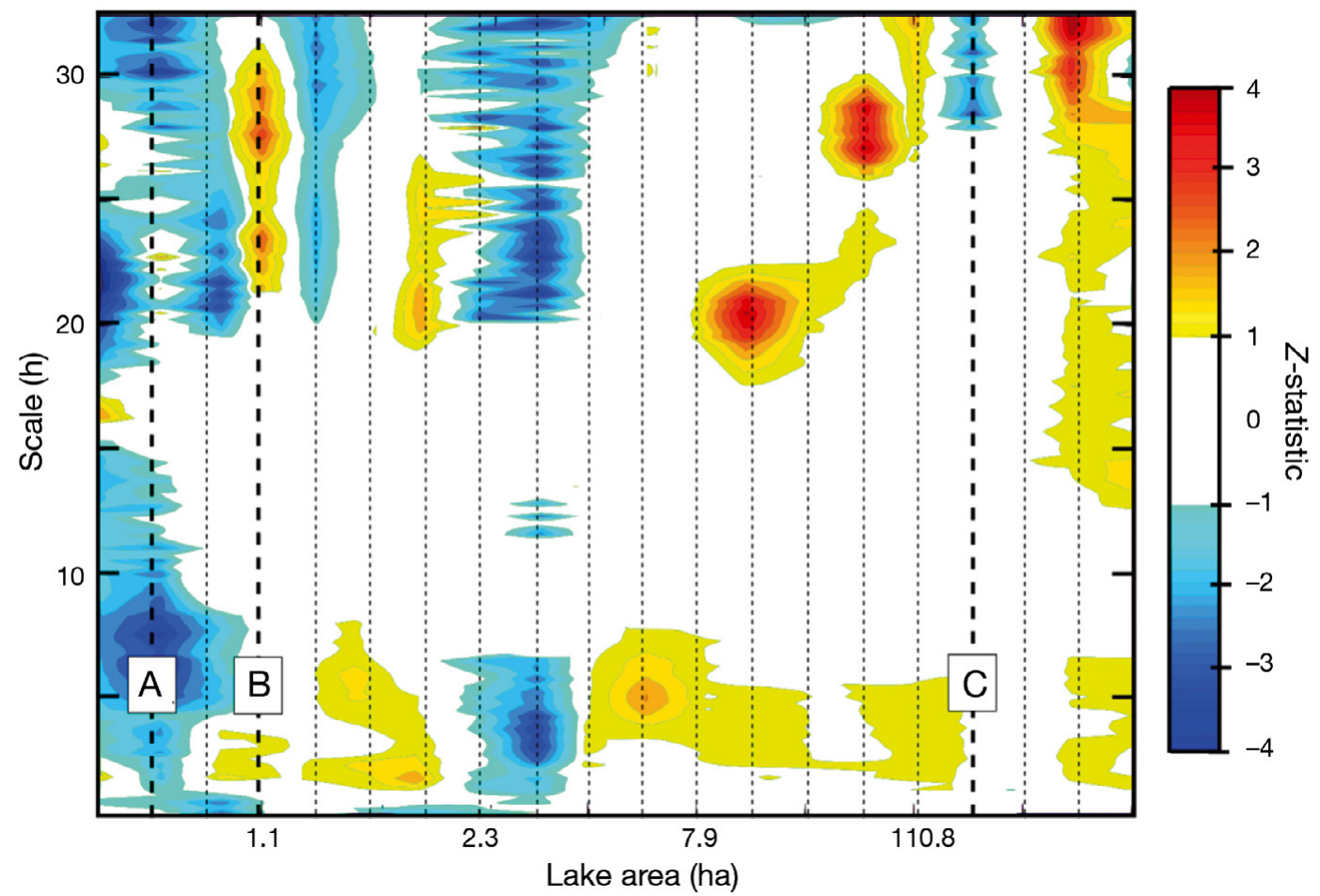

Fig. 6. Temperature correlation with dissolved oxygen (DO) for scales from 0.25 to $32 \mathrm{~h}$. Each lake is represented by a vertical dashed line. Labeled lines indicate the lakes that are featured in the analysis; A: Hummingbird Lake, B: Trout Bog, and C: Allequash Lake. White space represents areas where the driver had no significant effect on DO. The x-axis is categorical 


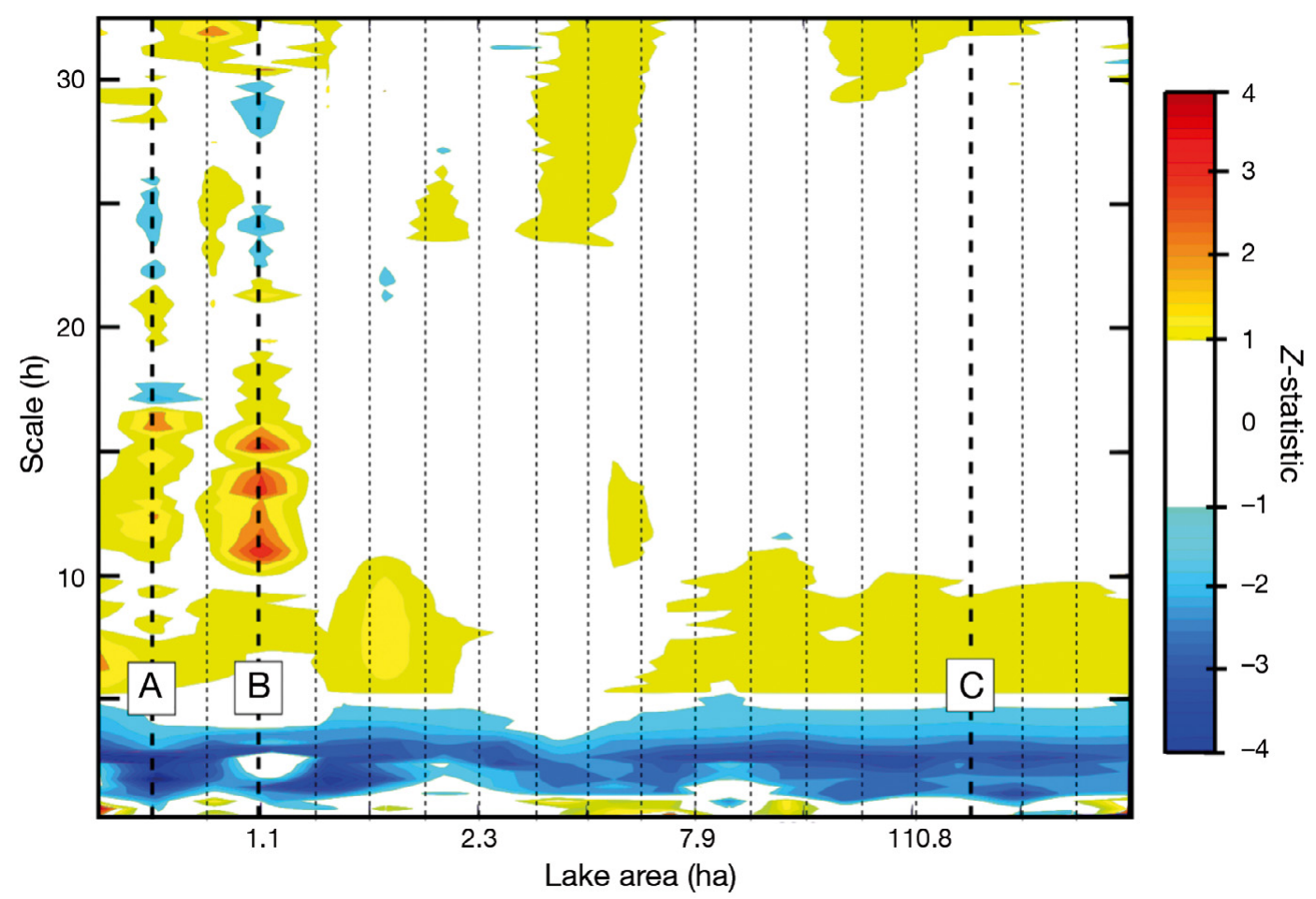

Fig. 7. Wind correlation with dissolved oxygen (DO) for scales from 0.25 to $32 \mathrm{~h}$. Each lake is represented by a vertical dashed line. Labeled lines indicate the lakes that are featured in the analysis; A: Hummingbird Lake, B: Trout Bog, and C: Allequash Lake. White space represents areas where the driver had no significant effect on DO. The $\mathrm{x}$-axis is categorical

tively correlated temperature effects. Scales lower than $7.5 \mathrm{~h}$ appear to contain significant temperature effects across the lake size gradient while the upper levels display less significance in lakes exceeding 3 ha with a notable exception in the second largest lake sampled. Temperature effects at the diel scale are not ubiquitous, presumably because PAR was the dominant driver at that scale.

The most apparent feature in the plot of wind speed significance (Fig. 7) is the strong negative band between scales ranging from 1 to $5 \mathrm{~h}$. Several small lakes including Hummingbird Lake and Trout Bog responded significantly over a much larger range of scales, with significant activity across the majority of the remaining scales analyzed.

\section{DISCUSSION}

It has long been known that primary production and ecosystem respiration are important DO fluxes in the surface waters of lakes. The underlying assumption is that observed pattern in DO is driven by primary production and respiration and that pattern in DO can be used to estimate these important ecosystem rates. However, complex pattern at the diel scale, and the absence of an obvious diel signal in some lakes (Fig. 3C), suggests the interaction of physical and biological processes manifests itself differently depending on the lake and the time scale. Can DO dynamics be used to estimate ecosystem metabolism at all time scales? More generally, what explains the scaledependent pattern in DO and how does that vary from lake to lake?

\section{Important scales for the examined drivers}

\section{PAR}

The strong relationship between PAR and DO at diel scales across most lakes (Fig. 5) suggests that photosynthetic and respiratory DO flux account for the majority of the diel signal as one would expect. While this relationship appears to hold for a narrow band of scales in lakes larger than 3 ha in the present study, several smaller lakes exhibited variability in PAR related to DO variability at other scales as well. The smallest lakes showed no measurable response to PAR fluctuations at any scale. Wind-driven DO mixing cannot sufficiently explain this apparent lack in response of DO to PAR; the smallest lakes each experienced at 
least one calm day in which correlation between PAR inputs and DO did not increase. This is likely not purely a size effect, because lakes that were slightly larger showed a large magnitude DO response to PAR. The smallest lakes in the study were bog lakes with high DOC, very low chlorophyll, and respiration values that far exceed gross primary production for the lakes (Hanson et al. 2003). The high concentration and refractory nature of DOC in these lakes would suggest a reasonably constant heterotrophic respiration. The color of these lakes also leads to a shallow euphotic zone, restricting primary production to about the top meter of the lake. Although this is speculation, under quiescent conditions of external drivers (wind and precipitation), we might see a distinct diel pattern, but when wind speed increases, mixing might dominate. This would explain how different lakes of the same size might have differing correlations with external driving variables. In addition, epilimnetic depth within small, humic lakes has been shown to correlate with lake fetch (von Einem \& Graneli 2010), further suggesting that wind plays an important role in governing the potential primary productivity influence. It is possible that primary productivity in these heterotrophic lakes does not produce enough DO to dominate the DO signal.

Several lakes had significant negative correlations between PAR and DO on sub-diel scales. For these lakes, the global wavelet transforms indicated a significant signal occurring over the 3 to $9 \mathrm{~h}$ time scales in both the DO transform and the PAR transform. The 2-dimensional influence plot for DO (Fig. 5) shows that these lakes have a strong negative correlation between DO and PAR at a sub-diel temporal scales, yet they maintain a positive correlation at the diel time scales. We have no plausible explanation for the negative correlation between DO and PAR at the sub-diel scale.

\section{Wind}

The effects of wind on DO are may be due to mixing and increased rates of gas exchange (MacIntyre \& Melack 1995). In stratified lakes, mixing has the effect of entraining metalimnetic water into the epilimnion. While the wind speeds are usually $<3 \mathrm{~m} \mathrm{~s}^{-1}$, which likely will not greatly affect $\mathrm{O}_{2}$ gas exchange (MacIntyre \& Melack 1995), sustained wind events of speeds $>3 \mathrm{~m} \mathrm{~s}^{-1}$ lasting from $30 \mathrm{~min}$ to $4 \mathrm{~h}$ are present in the raw data. At least one such event per lake was recorded during the sampling period. The wind events are correlated with a large drop in DO in surface waters (Fig. 7, Hummingbird Lake in particular). This may be a mixing response within the lake. A few of the lakes, especially smaller ones, showed a DO response to wind at other scales, indicating potential size-based sensitivity to the processes affected by wind. In every lake examined, wind consistently relates to DO variability over short time periods in scales ranging from minutes to hours.

\section{Temperature}

Temperature appears to relate to DO variability in broad bands occurring at both short and longer time scales. Work from a separate study on 2 of these lakes has suggested that internal waves may explain shortterm variation in DO signals (Hanson et al. 2008). If internal waves are driving the DO variability, it is possible that water beneath the sensor has lower DO in some lakes, whereas in others, that water is higher in DO. For example, large clear lakes in this region often have metalimnetic DO peaks (Ruttner 1963) and DO sensors placed near the metalimnion may record increasing DO and decreasing temperature when an internal wave passes the sensor. Temperature fluctuations related to DO at diel and greater scales show significance in most of the smaller lakes. The sign of the relationship to DO does not appear to be static across lakes, and indicates that another variable likely controls the directionality of the relationship. Although this may be a plausible explanation for why DO correlates with temperature at sub-diel time scales, internal waves were not quantified in the present study.

DO rarely relates to any of the drivers within scales ranging from about 8 to $15 \mathrm{~h}$ (Figs. 5-7). This may be due to minimal variation in DO at those scales. The global spectra for DO in the 3 exemplar lakes (Fig. 4) show little significant variability in these scales for 2 of the lakes. This pattern is repeated for almost all of the lakes surveyed (spectra not shown), with the exception of 2 lakes exhibiting negative $Z$-statistics at near-diel time scales (Fig. 5). While lakes in the present study had little DO variation at scales ranging from about 8 to $15 \mathrm{~h}$, others have found significant variability in tropical, shallow lakes (Ganf \& Horne 1975). It would be interesting to conduct a similar study in tropical lakes where different controls of $\mathrm{O}_{2}$ dynamics may operate.

Lake area appears to relate to the number of significant scales evident in the DO data (Fig. 4) as well as the number of scales explained by driver variables (Figs. 5-7). In larger lakes, the scale band explained by drivers tends to be narrower than the band explained in smaller lakes. In the present study, lakes that were smaller than about 5 ha appear to have these broader band relationships, although it is important to point out that lakes in Figs. 5-7 are not plotted across a continu- 
ous gradient of lake area. Furthermore, we cannot discriminate between lake area and its many correlates as drivers of the patterns. Lake area is highly correlated with other characteristics such as DOC concentration and littoral to pelagic area. These characteristics could influence DO signals in different ways. For example, smaller lakes in this region tend to have higher chromophoric dissolved organic matter (CDOM) concentrations (Hanson et al. 2007). CDOM rapidly attenuates irradiance input, leading to shallower mixed layers (Snucins \& Gunn 2000) that respond rapidly to varying external energy inputs (Houser 2006). Diel amplitudes of DO in macrophyte-rich littoral zones are much higher than pelagic amplitudes (Lauster et al. 2006) where sensors are typically placed. Horizontal advection between littoral and pelagic zones could change DO signals in unpredictable ways.

Lakes have been proposed as sensors for local and global change because they integrate the effects of terrestrial, climatic, and anthropogenic exogenous drivers (Williamson et al. 2008). How a lake responds to exogenous drivers over long time scales may be determined by a number of physical and biological characteristics (Adrian et al. 2009). At short time scales, our results show how lake area influences its response to exogenous drivers. Smaller lakes tend to have a greater magnitude of response to drivers, and that response smears across a range of time scales (Figs. 5-7). How lakes respond across broader scales to climate-driven or land use-driven changes in driving variables will undoubtedly be complex. Using the methods described here, one can identify the scale or scales at which a particular process of interest influences observed variability and remove the interfering patterns of other processes responding to other exogenous drivers. Filtering confounding noise in this way can reduce uncertainty in rate estimates, such as metabolism (Coloso et al. 2008). The analysis used here can be expanded to incorporate any number of potential drivers measured at regular intervals, making the analysis particularly useful for sensor network platforms.

Acknowledgements. We thank all of the reviewers whose suggestions greatly improved the manuscript. This research was supported by the National Science Foundation through the North Temperate Lakes LTER program.

\section{LITERATURE CITED}

Addison PS (2002) The illustrated wavelet transform handbook. Institute of Physics Publishing, London

> Adrian R, O'Reilly CM, Zagarese H, Baines SB and others (2009) Lakes as sentinels of climate change. Limnol Oceanogr 54:2283-2297

Barkai N, Seung HS, Sompolinsky H (1993) Scaling laws in learning of classification tasks. Phys Rev Lett 70 : $3167-3170$

Boegman L, Imberger J, Ivey GN, Antenucci JP (2003) Highfrequency internal waves in large stratified lakes. Limnol Oceanogr 48:895-919

Caruana R, Lawrence S, Giles CL (2000) Overfitting in neural nets: backpropagation, conjugate gradient, and early stopping. In: Touretzky D (ed) Advances in neural information processing systems. Morgan Kaufmann Publishers, San Francisco, CA, p 402-408

Cole JJ, Pace ML, Carpenter SR, Kitchell JF (2000) Persistence of net heterotrophy in lakes during nutrient addition and food web manipulations. Limnol Oceanogr 45: $1718-1730$

Coloso JJ, Cole JJ, Hanson PC, Pace ML (2008) Depthintegrated, continuous estimates of metabolism in a clearwater lake. Can J Fish Aquat Sci 65:712-722

> Eckert W, Imberger J, Saggio A (2002) Biogeochemical response to physical forcing in the water column of a warm monomictic lake. Biogeochemistry 61:291-307

Ganf GG, Horne AJ (1975) Diurnal stratification, photosynthesis, and nitrogen fixation in a shallow, equatorial lake (Lake George, Uganda). Freshw Biol 5:13-39

Hanson PC, Bade DL, Carpenter SR, Kratz TK (2003) Lake metabolism: relationships with dissolved organic carbon and phosphorus. Limnol Oceanogr 48:1112-1119

> Hanson PC, Carpenter SR, Armstrong DE, Stanley EH, Kratz TK (2006) Lake dissolved inorganic carbon and dissolved oxygen: changing drivers from days to decades. Ecol Monogr 76:343-363

> Hanson PC, Carpenter SR, Cardille JA, Coe MT, Winslow LA (2007) Small lakes dominate a random sample of regional lake characteristics. Freshw Biol 52:814-822

Hanson PC, Carpenter SR, Kimura N, Wu C, Cornelius SP, Kratz TK (2008) Evaluation of metabolism models for freewater dissolved oxygen methods in lakes. Limnol Oceanogr Methods 6:454-465

Haykin S (1994) Neural networks: a comprehensive foundation. Prentice Hall PTR, Upper Saddle River, NJ

Hodges BR, Imberger J, Saggio A, Winters KB (2000) Modeling basin-scale internal waves in a stratified lake. Limnol Oceanogr 45:1603-1620

> Houser JN (2006) Water color affects the stratification, surface temperature, heat content, and mean epilimnetic irradiance of small lakes. Can J Fish Aquat Sci 63: $2447-2455$

Jonsson A, Åberg J, Lindroth A, Jansson M (2008) Gas transfer rate and $\mathrm{CO} 2$ flux between an unproductive lake and the atmosphere in northern Sweden. J Geophys Res 113: G04006. doi:10.1029/2008JG000688

Keitt TH, Fischer J (2006) Detection of scale-specific community dynamics using wavelets. Ecology 87:2895-2904

Kratz TK, Arzberger P, Benson BJ, Chiu CY and others (2006) Towards a global lake ecological observatory network. Publ Karelian Inst 145:51-63

> Lauster GH, Hanson PC, Kratz TK (2006) Gross primary production and respiration differences among littoral and pelagic habitats in northern Wisconsin lakes. Can J Fish Aquat Sci 63:1130-1141

Le Cun Y, Denker JS, Solla SA (1990) Optimal brain damage. In: Touretzky D (ed) Advances in neural information processing systems 2. Morgan Kaufmann Publishers, San Francisco, CA, p 598-605

- MacIntyre S, Melack J (1995) Vertical and horizontal transport in lakes: linking littoral, benthic, and pelagic habitats. J N Am Benthol Soc 14:599-615

MacIntyre S, Romero JR, Kling GW (2002) Spatial-temporal 
variability in surface layer deepening and lateral advection in an embayment of Lake Victoria, East Africa. Limnol Oceanogr 47:656-671

MacIntyre S, Clark JF, Jellison R, Fram JP (2009) Turbulent mixing induced by nonlinear internal waves in Mono Lake, California. Limnol Oceanogr 54:2255-2272

Odum HT (1956) Primary production in flowing waters. Limnol Oceanogr 1:102-117

Podsetchine V, Schernewski G (1999) The influence of spatial wind inhomogeneity on flow patterns in a small lake. Water Resour 33:3348-3356

Ruttner F (1963) Fundamentals of limnology, 3rd edn. University of Toronto Press, Toronto

Saggio A, Imberger J (1998) Internal wave weather in a stratified lake. Limnol Oceanogr 43:1780-1795

Snucins E, Gunn J (2000) Interannual variation in the thermal

Editorial responsibility: Max Tilzer,

Konstanz, Germany structure of clear and colored lakes. Limnol Oceanogr 45: 1639-1646

Staehr PA, Sand-Jensen K (2007) Temporal dynamics and regulation of lake metabolism. Limnol Oceanogr 52: $108-120$

Thorpe SA, Jiang R (1998) Estimating internal waves and diapycnal mixing from conventional mooring data in a lake. Limnol Oceanogr 43:936-945

Williamson CE, Kratz TK, Dodds W, Palmer MA (2008) Lakes and streams as sentinels of environmental change in terrestrial and atmospheric processes. Front Ecol Environ 6: $247-254$

von Einem J, Graneli W (2010) Effects of fetch and dissolved organic carbon on epilimnion depth and light climate in small forest lakes in southern Sweden. Limnol Oceanogr 55:920-930

Submitted: March 26, 2008; Accepted: March 26, 2010 Proofs received from author(s): May 3, 2010 